\title{
Perspectives on the use of a telehealth service-delivery model as a component of school-based occupational therapy practice: Designing a user-experience
}

\author{
Daniel Rortvedt* and Karen Jacobs \\ Department of Occupational Therapy, Boston University, College of Health \& Rehabilitation Sciences: Sargent \\ College, Boston, MA, USA
}

Received 2 September 2017

Accepted 24 May 2018

\begin{abstract}
.
BACKGROUND: Telehealth is an accepted service-delivery model in a variety of health professions, including occupational therapy. Telehealth holds potential for school-based occupational therapy evaluation, intervention, consultation, monitoring, and supervision. As the use of telehealth becomes prevalent, it will be important to describe the benefits and barriers to potential types of occupational therapy evaluation, intervention, consultation, monitoring, and supervision delivered via a telehealth service-delivery model. Querying stakeholder perceptions of telehealth may help guide additional precipitating factors that have not yet been explored.

OBJECTIVE: This study gathers information regarding perceptions, perceived barriers, and benefits of the use of telehealth in school-based occupational therapy practice.

METHODS: School-based occupational therapy practitioners (OTP), district administrators, and related technology staff were invited to complete a survey intended to explore attitudes about the use of telehealth.

RESULTS: $28.57 \%$ of respondents stated that their districts were likely to adopt the use of telehealth. Participants noted perceived barriers and benefits to the use of telehealth.

CONCLUSIONS: This study provides preliminary feedback regarding school-based OTP and administrator perceptions of telehealth as a component of school-based OT practice.
\end{abstract}

Keywords: Pediatrics, telerehabilitation, telemedicine, telepractice, end-user acceptance

\section{Introduction}

The use of telehealth ${ }^{1}$ is an accepted servicedelivery model in a variety of health professions, including occupational therapy (OT) [1]. The

*Address for correspondence: Daniel Rortvedt, Elmhurst College, Cureton Hall 149, 190 S. Prospect Avenue, Elmhurst, IL 60126, USA. E-mail: daniel.rortvedt@elmhurst.edu.

${ }^{1}$ Definition of "telehealth" (from the American Occupational Therapy Association): "The application of evaluative, consultative, preventative, and therapeutic services delivered through telecommunication and information technologies," (AOTA, 2014, p. S69). evidence literature describes promising uses for telehealth within the health professions. A case study by Ritchie, Miller, \& Antle [2], for example, found no significant differences between ergonomics assessments delivered via telehealth when compared to in-person assessment [2]. Additionally, Cotton, Russell, Johnston, \& Legge [3] found no significant differences in therapist training results whether training was delivered via telehealth methods (live video-conferencing, individual and group online modules) or in-person [3]. 
School-based occupational therapy practitioners (OTPs) currently experience high caseload/ workloads, and a shortage of occupational therapy (OT) providers exists within the United States [4]. While a collaborative consultation OT servicemodel has been shown to improve student outcomes [5], therapist caseloads and difficulty coordinating schedules lead to limited time for collaboration between occupational therapist and classroom teacher/educational team. The evidence literature shows emerging support for the use of a telehealth service-delivery model in pediatric occupational therapy practice [6-14, 18]. The use of telehealth in pediatric occupational therapy has been shown to be effective by increasing access to specialist care and preventing delays in provision of services [9], providing increased collaboration and carry-over of treatment strategies [15], and improving overall therapist/client satisfaction [10, 16-18]. Research on telehealth in general provides support for client satisfaction with the use of this service-delivery format [19-23]. The use of telehealth holds potential for school-based occupational therapy evaluation, intervention, consultation, monitoring, and supervision [24]. Despite emerging evidence, the use of telehealth as a component of school-based occupational therapy practice is limited. Previous studies have explored school-based Speech \& Language Pathologists' (SLP) qualitative perspectives on telehealth in the SLP community [25], but similar studies are limited relative to school-based occupational therapy.

Occupational therapy students are beginning to acquire telehealth-related skills in accredited OT programs [9]. Additionally, The Accreditation Council for Occupational Therapy Education (ACOTE) requires, under Standard B.1.8, that students demonstrate an understanding of technology, including but not limited to, technologies such as the use of telehealth $[9,26]$. Reimbursement for occupational therapy services delivered via telehealth is not universal [9] and, as of this writing, reimbursement policies for occupational therapy services delivered via telehealth vary on a state-by-state basis.

As the use of telehealth becomes more prevalent, it will be important to describe and differentiate the benefits of and barriers to potential types of occupational therapy evaluation, intervention, consultation, monitoring, and supervision delivered via a telehealth service-delivery model [24]. Additionally, it will be important to consider the potential uses of telehealth as a delivery model for conducting unobtrusive classroom observations [24], and multi-tiered System of
Supports (MTSS) services for students who do not currently receive formal special education services. Querying stakeholder perceptions of telehealth may help guide additional precipitating factors that have not yet been explored [25].

End-user acceptance of interactive technologies is listed as a continued barrier to the use of telehealth [27] and clinician satisfaction is a critical factor for the widespread acceptance and use of telehealth [28]. Further information is needed on how best to promote clinician satisfaction with the use of this service delivery model. Hersch et al. [29], explored occupational therapists' perceptions of the use of a telehealth service-delivery model in the Houston, Texas area. Of the 51 survey respondents, $22 \%$ reported using a telehealth service-delivery model to conduct evaluations or deliver interventions. These results suggest that a majority of occupational therapy practitioners do not currently use telehealth in clinical practice. However, $52 \%$ of respondents felt that telehealth has the potential to improve clinical practice. The authors noted a need for more education and training in telehealth technology for OT practitioners [29].

\subsection{Research questions}

1. What are the potential uses of a telehealth service-delivery model to augment schoolbased occupational therapy practice?

2. What are the perceived barriers and supports to the implementation of this service-delivery model in a school district setting?

\section{Methods}

School-based occupational therapists, certified occupational therapy assistants, district administrators, and technology staff representing three school districts in a suburban, Midwestern area were invited to complete an online survey intended to explore their attitudes about the use of telehealth as a component of school-based occupational therapy practice. School districts were identified based on convenience sampling. School districts were part of suburban cities which had overall populations between $\sim 32,000$ and $\sim 150,000$, with average household incomes ranging from $\$ 89,000-110,000$ (U.S. Census Bureau Quick Facts, 2016) [30]. A link to the online survey (administered via the Qualtrics software platform) was distributed to participants via e-mail. A total of 67 participants were invited to complete the online 
survey. Participants provided consent to participate in the study via a questionnaire item prior to beginning the survey. In order to ensure confidentiality of information, all data collection materials and data files were stored in a secure electronic database on the SAR-Nas server (Boston University). Survey responses were anonymous to ensure confidentiality. Open-ended responses were analyzed using a technique closely matched to directed content analysis [31]. Common themes were identified when possible. This survey was a component of a doctoral project in the Department of Occupational Therapy at Boston University. Permission to complete research within each individual school district was granted. The Boston University Institutional Review Board granted exempt approval for this study.

\section{Results}

Of 67 individuals contacted, 27 respondents completed the online survey ( $40.3 \%$ response rate). All 27 participants gave their consent to participate in the survey. Not all participants completed each item on the survey, thus response rates varied across survey items.

Participants $(n=26)$ identified their roles in the school districts they represented, their type of school setting, and their number of years of experience. See Table 1 for a description of demographic information.

Participants identified whether their school districts have a policy regarding the use of telehealth, commented on the likelihood of telehealth adoption within their school districts, and commented on their level of interest in a proposed telehealth educational program. Results are noted in Table 2.

\subsection{Perceived benefits of telehealth}

Participants $(n=17)$ described potential benefits of the use of telehealth as a component of school-based OT practice. Open-ended responses were organized using content analysis. Similar responses were identified and organized around common themes. The following perceived benefit categories were identified: 1) Logistics, 2) MTSS/classroom observations, 3) Support for homebound students, 4) Collaboration, consultation, \& supervision, and 5) Other perceived benefits. Examples of participant responses within each category are provided in Table 3.

\subsection{Perceived barriers to Telehealth}

Participants $(n=19)$ described potential barriers to the use of telehealth as a component of school-based OT practice. Open-ended responses were organized using content analysis. Similar responses were identified and organized around common themes. The following perceived barrier categories were identified: 1) Logistics, 2) Lack of physical contact, 3) Student factors, 4) Privacy concerns, 5) Difficulty completing student evaluations, and 6) Other perceived barriers. Examples of participant responses within each category are provided in Table 4.

Table 1

Demographic information of survey participants $(n=26)$

\begin{tabular}{lcc}
\hline Job title/role & Number of respondents & Percentage \\
\hline Occupational Therapist & 11 & $42.31 \%$ \\
Certified Occupational therapy Assistant & 3 & $11.54 \%$ \\
Therapy Supervisor & 1 & 3.85 \\
Special Education Administrator & 6 & $23.08 \%$ \\
Instructional Technology Staff & 2 & $7.69 \%$ \\
Other & 3 & $11.54 \%$ \\
\hline Number of Years Experience & Number of respondents & Percentage \\
\hline Less than 5 years & 4 & $15.38 \%$ \\
Between 5-10 years & 2 & $7.69 \%$ \\
Between 10-15 years & 5 & $19.23 \%$ \\
Between 15-30 years & 11 & $42.31 \%$ \\
$30+$ years & 4 & $15.38 \%$ \\
\hline Type of school setting & Number of respondents & Percentage \\
\hline Public school (population $>100,000)$ & 11 & $42.31 \%$ \\
Public school (population $<100,000)$ & 15 & $57.69 \%$ \\
\hline
\end{tabular}


Table 2

District policy, likelihood of telehealth adoption, and interest in telehealth educational program

\begin{tabular}{lcc}
\hline District policy on telehealth? & Number of respondents & Percentage \\
\hline Yes & 1 & $3.85 \%$ \\
No & 15 & $57.69 \%$ \\
Don't Know & 10 & $38.46 \%$ \\
Total & 26 & \\
\hline Likelihood of adoption of telehealth? & Number of respondents & Percentage \\
\hline Not likely & 3 & $14.29 \%$ \\
Likely & 6 & $28.57 \%$ \\
Extremely likely & 0 & $0 \%$ \\
Already use telehealth & 0 & $0 \%$ \\
Not sure/prefer not to answer & 12 & $57.14 \%$ \\
Total & 21 & \\
\hline Interest in educational program? & 9 & Percentage \\
\hline Yes & 9 & $42.86 \%$ \\
No & 3 & $42.86 \%$ \\
Don't know & 21 & $14.29 \%$ \\
Total & Number of respondents \\
\hline Preferred format of educational program & Number of respondents & Percentage \\
\hline Online presentation \& online discussion & 4 & $20.00 \%$ \\
In-person presentation \& in-person discussion & 1 & $5.00 \%$ \\
In-person presentation \& online discussion & 3 & $15.00 \%$ \\
Other & 2 & $10.00 \%$ \\
N/A & 10 & $50.00 \%$ \\
Total & 20 & \\
\hline
\end{tabular}

Table 3

Perceived benefits of telehealth

\begin{tabular}{|c|c|}
\hline Perceived Benefit Category & Example Response \\
\hline Logistics & $\begin{array}{l}\text { "Less travel for the therapist" } \\
\text { "Better use of therapist's time" } \\
\text { "Information delivered faster and to more people quickly." }\end{array}$ \\
\hline MTSS/classroom observations & $\begin{array}{l}\text { "Telehealth may be beneficial for parents and teachers to gain procedural knowledge of } \\
\text { therapeutic interventions for collaborative and consultative purposes. The focus could also be } \\
\text { on a MTSS level." }\end{array}$ \\
\hline Support for homebound students & "Telehealth can be a viable service delivery model for homebound students with disabilities." \\
\hline Collaboration, consultation, \& supervision & "Supervision of other providers (COTA, classroom assistants, etc)" \\
\hline Other perceived benefits & $\begin{array}{l}\text { "It is difficult to find therapists in this area and telehealth approach would be an answer to that } \\
\text { problem. } \\
\text { "[It] would be great to use this tool for mentoring new graduates that are new to our school } \\
\text { system." }\end{array}$ \\
\hline
\end{tabular}

\subsection{Participant comments/questions regarding Telehealth}

Participants $(n=14)$ identified comments and/or questions regarding telehealth as a component of school-based OT practice. Open-ended responses were organized using content analysis. Similar responses were identified and organized around four common themes: 1) Questions about telehealth, 2) "Pro-telehealth" comments, 3) Telehealth "cautionary" comments, and 4) Neutral comments. Examples of participant responses within each category are provided in Table 5.
Participants were also asked to comment on any research they were aware of (other than this study) on the use of telehealth within the district/organization they represent. No participant stated that he or she was aware of any other research on telehealth within their organizations $(n=15)$.

\section{Discussion}

According to results, participants identified several perceived benefits to the use of telehealth, including cost-savings, addressing staffing/provider shortages, 
Table 4

Perceived barriers of telehealth

\begin{tabular}{ll}
\hline Perceived Barrier Category & Example Response \\
\hline Logistics & "Training related to navigating the technology and use of equipment" \\
& "Ensuring that the student is somehow supervised at the site before, during, and after the \\
therapy session is complete would need to be considered..." & "I think the most obvious is the human connection that occurs naturally from people \\
physically being in the same room with each other." & "If the student has difficulty following directions or sustaining focus without physical prompts \\
Lack of physical contact & or guidance, then the therapy session may be less successful via a telehealth model." \\
Student factors & "We have the available hardware, but have concerns about which software would support \\
telehealth while protecting the privacy and security of our clients." & "Evaluation may be difficult to conduct through the telehealth model. Hands on evaluation to \\
Privacy concerns & $\begin{array}{l}\text { assess the child's physical status may be the most optimal way to gather data regarding body } \\
\text { structures and systems." } \\
\text { "Economically disadvantaged families may not have access to the internet or sufficient }\end{array}$ \\
Other perceived barriers & $\begin{array}{l}\text { service on a smart phone to communicate with the related service personnel." } \\
\text { "There is a lack of understanding of telehealth among all stakeholders, including school } \\
\text { district administrators, therapists, and parents." }\end{array}$ \\
\hline
\end{tabular}

Table 5

Questions and comments about telehealth

\begin{tabular}{ll}
\hline Category & Example Response \\
\hline Questions about telehealth & "Does this type of therapy allow students to participate with one another during therapy sessions via \\
& telehealth?" \\
& "What is the best technology avenue or most efficient?" \\
& "What is the liability of therapists using this avenue of intervention?" \\
"Pro-telehealth" comments & where funds will not allow for hiring of OTs and even larger districts where OTs are spread too thin." \\
Telehealth "cautionary" comment & "I have concerns about districts pushing the limits of what should and shouldn't be done through \\
teletherapy, as it may be less costly than in person therapy." & "I would like to view research to see the ways to implement and what the barriers may actually be \\
Neutral comments & since I am not familiar."
\end{tabular}

allowing flexible scheduling, utilizing telehealth for MTSS and unobtrusive classroom observations, providing support for students on homebound services due to medical issues, enhancing collaboration, consultation, and supervision, and other perceived benefits. Additionally, participants identified several perceived barriers to the use of telehealth, including access to/availability of equipment and training required to implement, scheduling issues, difficulty with supervision of students or staff, overall logistics issues, lack of physical contact, difficulty building rapport, attention to task and independence of student, generalization of skills, privacy concerns, difficulty completing student evaluations, and other perceived barriers.

The use of telehealth in pediatric occupational therapy practice has the potential to increase access to specialist care and prevent delays in the provision of services [9], provide increased collaboration and carry-over of treatment strategies [15], and improve overall therapist/client satisfaction $[10,16$, 17, 18]. As the use of telehealth becomes prevalent, it will be important to further describe and differentiate the benefits and barriers to potential types of occupational therapy evaluation, intervention, consultation, monitoring, and supervision delivered via this service-delivery model [24]. This study provides preliminary feedback regarding school-based OTP and administrator perceptions of telehealth as a component of school-based OT practice. According to results of this pilot survey, within these three school districts in a suburban area of the Midwestern United States, OTP currently do not use a telehealth service-delivery model. According to Nissen \& Brockevelt [32], education is a critical factor necessary to promote successful implementation of telehealth in clinical practice [32]. Additional theorists, including Rogers (Diffusion of Innovation) 
[33], and Knowles (Adult Learning Theory) [34], propose that education can play a role in adoption of new technologies for adult learners. According to the results of this pilot survey, 9 of 21 participants $(42.86 \%)$ expressed an interest in participating in an educational program about the use of telehealth. The delivery of a participant-centered educational program could further expand participant knowledge of telehealth and, in turn, increase the likelihood of adoption of the use of telehealth as a component of clinical practice. Additional research is needed to explore the perceived (and real) barriers and supports to the use of telehealth as a component of school-based occupational therapy practice. As state and federal telehealth policy and reimbursement factors evolve, OTP may become more likely to utilize a telehealth service-delivery model as a component of practice, thus creating expanded opportunities for clinical research.

\section{Limitations}

In addition to a limited response rate and small sample size, practitioners who responded to this survey do not currently utilize telehealth technologies. A survey of OTP who currently use telehealth as a component of school-based practice may yield alternate results. Additionally, this survey might be conducted on a multi-state or national level to identify common themes across diverse geographical areas.

\section{Conclusion}

The use of telehealth as a component of schoolbased occupational therapy service-delivery is a complex issue requiring mindful consideration. This study provides preliminary feedback regarding school-based OTP and administrator perceptions of telehealth as a component of school-based OT practice. The use of telehealth has the potential to promote access to OT services in specific school therapy arrangements and contexts via enrichment of collaborative consultation with parents/teachers, provision or supplementation of service-delivery in rural areas and/or school districts experiencing high therapist caseloads/workloads, and other specific student situations that might warrant a telehealth approach. Additional considerations, including privacy, security, ethical, reimbursement, liability, and licensure issues, must be explored and addressed. As practitioners, if we envision the use of telehealth as an enhancement to traditional OT service-delivery in the school setting, how are we to proceed? If situations arise within school districts that warrant a telehealth-based approach, are school teams comfortable addressing it? If not, how are we to ensure that teams are equipped with this knowledge and technology? Additional collaboration between occupational therapy researchers and clinicians may provide preliminary answers to these important questions.

\section{Acknowledgments}

This study was completed as a component of a post-professional doctorate in occupational therapy program at Boston University, Sargent College of Health \& Rehabilitation Sciences. Portions of this document (sometimes in slightly different forms) were previously published by the Robert J. Waters Center for Telehealth and e-Health Law.

\section{Conflict of interest}

None to report.

\section{References}

[1] American Occupational Therapy Association. Occupational therapy practice framework: Domain and process. Am J Occup Ther. 2014;68(Suppl.1):S1-48.

[2] Ritchie CW, Miller LL, Antle DM. Telehealth for ergonomics assessment: A Case studydetailing key considerations for implementing a telehealth approach to office ergonomics. Work. 2017;57(4):469-73. Available from: doi: 10.3233/WOR-172579

[3] Cotton Z, Russell T, Johnston V, Legge J. Training therapists to perform pre-employmentfunctional assessments: A Telerehabilitation approach. Work. 2017;57(4):475-82. Available from: doi: 10.3233/WOR-172578

[4] Educator Supply and Demand Report. (2015-2016). American Association for Employmentin Education (AAEE), pp. 1-42.

[5] Villeneuve M. A Critical examination of school-based occupational therapy collaborative consultation. Can J Occup Ther. 2009;76(Jul Special Issue):206-18 .

[6] The American Occupational Therapy Association Advisory Opinion for the Ethics Commission: Telehealth. (2013). Available from https://www.aota.org/ /media/Corporate/ Files/Practice/Ethics/Advisory/telehealth-advi sory.pdf

[7] Cason J. A pilot telerehabilitation program: Delivering early intervention services to rural families. International Journal of Telerehabilitation. 2009;1(1):29-38.

[8] Cason J. Tele-health opportunities in occupational therapy through the affordable care act. Am J Occup Ther. 2012;66(2):131-6. 
[9] Cason J. Tele-health: A Rapidly developing service delivery model for occupationaltherapy. International Journal of Tele-Rehabilitation. 2014;6(1):29-36.

[10] Criss MJ. School-based tele-rehabilitation in occupational therapy: Using tele-rehabilitation technologies to promote improvements in student performance. International Journal of Tele-rehabilitation. 2013;5(1):39-46.

[11] Gallagher TE. Augmentation of special-needs services and information to students andteachers "ASSIST"-a tele-health innovation providing school-based medicalinterventions. Hawaii Medical Journal. 2004;63(10):300-9.

[12] Heimerl S, Rasch N. Delivering development occupational therapyconsultation services through telehealth. Developmental Disabilities Special Interest Section Quarterly. 2009; 32(3):1-4.

[13] Benham S, Gibbs V. Exploration of the effects of telerehabilitation in a school-basedsetting for at-risk youth. International Journal of Telerehabilitation. 2017;9(1): $39-46$.

[14] Verburg G, Borthwick B, Bennett B, Rumney P. Online support to facilitate there integration of students with brain injury: Trials and errors. Neuro Rehabilitation. 2003;18: 113-23.

[15] Gibbs V, Toth-Cohen S. Family-centered occupational therapy andtelerehabilitation for children with autism spectrum disorders. Occup Ther Health Care. 2011;25(4):298-314.

[16] Ashburner J. Remote versus face-to-face delivery of early intervention programs forchildren with autism spectrum disorders: Perceptions of rural families and service providers. Research in Autism Spectrum Disorders. 2016;23:1-14.

[17] Reifenberg G, Gabrosek G, Tanner K, Harpster K, Proffitt R, Persch A. Feasibility of pediatric game-based neurorehabilitation using telehealth technologies: A Case report. Am J Occup Ther. 2017;71(3):7103190040p1-7103190040p8.

[18] Zylstra SE. Evidence for the use of telehealth in pediatric occupational therapy. Journal of Occupational Therapy, Schools, \& Early Intervention. 2013;6(4):326-55.

[19] Crutchley S, Campbell M. Telespeech therapy pilot project: Stakeholder satisfaction. International Journal of Telerehabilitation. 2010;2(1):23-30.

[20] Kairy D, Lehoux P, Vincent C, Visintin M. A Systematic review of clinical outcomes, clinical process, healthcare utilization and costs associated with telerehabilitation. Disabil Rehabil. 2009;31:427-47.
[21] Lai JC, Woo J, Hui E, Chan WM. Telerehabilitation - A new model for community-basedstroke rehabilitation. J Telemed Telecare. 2004;10:199-205.

[22] Russell T, Buttrum P, Wootton R, Jull G. Internet-based outpatient telerehabilitation for patients following total knee arthroplasty: A randomized controlled trial. J Bone Joint Surg Am. 2010;93:113-20.

[23] Wu G, Keyes LM. Group tele-exercise for improving balance in elders. Telemed J E Health. 2006;12:561-70.

[24] Cason J, Hartmann K, Jacobs K, Richmond T. Tele-health. Am J Occup Ther. 2013;67(6):S69-S90.

[25] Tucker JK. Perspectives of speech-language pathologists on the use of tele-practice inschools: The Qualitative view. International Journal of Tele-rehabilitation. 2012;4(2): 47-60.

[26] Accreditation council for occupational therapy education (ACOTE) standards andinterpretive guide. (2013). Retrieved from https://www.aota.org/ /media/Corporate/ Files/EducationCareers/Accredit/Standards/2011-Standard s-and-Interpretive-Guide.pdf

[27] Cason J, Richmond T. Telehealth opportunities in occupational therapy. In Kumar S, Cohn Ellen R, eds. \& Springer Link provider. (2013). Telerehabilitation. pp. 139-162. London: Health Informatics, 2012.

[28] Mashima PA, Doarn CR. Overview of telehealth activities in speech-language pathology. Telemed J E Health. 2008;14:1101-17.

[29] Hersch G, Kao B, Melton L, Pancheri K. Tele-health usage by occupational therapy practitioners. Am J Occup Ther. 2015;69:6911510038p1.

[30] U.S. Census Bureau Quick Facts. 2016. Retrieved from https://www.census.gov/quickfacts/fact/table/US/ PST045217

[31] Hsieh H, Shannon S. Three approaches to qualitative content analysis. Qual Health Res. 2005;15(9):1277-88.

[32] Nissen RM, Brockevelt BL. The effect of education on student perceptions about telehealth. International Journal of Health Sciences. 2016;4(4):5-10.

[33] Rogers E. Diffusion of innovations, 3rd ed. New York, London: Free Press; Collier Macmillan, 1983.

[34] Adult Learning Theories. 2011. Retrieved from https://lincs. ed.gov/sites/default/files/11_\%20TEAL_Adult_Learning_ Theory.pdf 